\title{
Cross-linked, polyurethane-based, ammonium poly(ionic liquid)/ionic liquid composite films for organic vapor suppression and ion conduction
}

\author{
Dylan I. Mori ${ }^{a}$, Rhia. M. Martin ${ }^{a, b}$, Richard D. Noble ${ }^{b}$, and Douglas L. Gin ${ }^{a, b,} *$ \\ ${ }^{a}$ Department of Chemistry and Biochemistry, University of Colorado, Boulder, CO 80309, United States \\ ${ }^{\mathrm{b}}$ Department of Chemical and Biological Engineering, University of Colorado, Boulder, CO 80309, United States \\ * Corresponding author at: Department of Chemistry and Biochemistry, University of Colorado, CO 80309, United \\ States. Tel.: +1 303492 7640. E-mail address: gin@ spot.colorado.edu
}

Keywords: ionic liquid, polyurethane, ammonium, organic vapor barrier, ion conductivity.

\begin{abstract}
:
A series of ammonium-diol and -triol ionic liquid (IL) monomers were synthesized and used in stepgrowth polymerization with the commercial di-isocyanate monomer, toluene-di-isocyanate (TDI), in the presence of free ammonium IL to form new curable ammonium-based polymerized ionic liquid/ionic liquid (PIL/IL) composite film coatings. The use of polyurethane chemistry allows for the near-complete curing of the alcohol and isocyanate monomers to yield solid, homogeneous, cross-linked polyurethanebased PIL/IL composite materials with no volatile side product formation. The physical properties and curing rates of these PIL/IL films were altered by tailoring the structures of the ammonium-alcohol IL monomers, the ratio of the linear vs. cross-linking IL monomers employed, and the amount of free IL in the curing reactions. Although ammonium-based PILs have been reported to be less thermally and electrochemically stable than their imidazolium counterparts in the literature, TGA results indicated a $T_{\text {onset }}$ of up to $300{ }^{\circ} \mathrm{C}$ under air for the ammonium PIL/IL composites prepared in this study. These new $\mathrm{PIL} / \mathrm{IL}$ materials were also tested as curable coatings in a toxic industrial chemical (TIC) vapor suppression and liquid uptake assay using $o$-dichlorobenzene $(o-\mathrm{DCB})$ as a simulant for polychlorinated biphenyls. The curable PIL/IL coatings were found to suppress $88 \%$ of the $o$-DCB vapor on $o$-DCBcontaminated painted steel substrates and $79 \%$ of the $o$-DCB vapor on $o$-DCB-contaminated rubber substrates, relative to uncoated control samples. However, although effective for TIC vapor suppression, these ammonium PIL/IL coatings only sorbed less than 50\% of the applied liquid $o$-DCB from the same test substrates, making them slightly less effective for this latter application than previously reported imidazolium-based curable PIL/IL coatings. These materials exhibited comparable ionic conductivity values to other types of PIL/IL systems previously reported in the literature. However, it was found that the more heavily cross-linked ammonium-based PIL/IL films were more prone to free IL leach-out at higher temperatures, leading to their unexpectedly higher ionic conductivity at elevated temperatures.
\end{abstract}




\section{Introduction}

Ionic liquids (ILs) (i.e., organic salts that are liquids at temperatures $\leq 100^{\circ} \mathrm{C}$ ) have received considerable attention in the materials community because of their unique set of physical and chemical properties. These properties include high intrinsic ion conductivity, very low vapor pressure, high uptake of $\mathrm{CO}_{2}$ compared to other light gases, high thermal and electrochemical stability, and high structural modularity for facile property tuning. Consequently, ILs have been used in many applications where this collection of properties is advantageous (e.g., as low-volatility ion-conducting media in electrochemical devices, as $\mathrm{CO}_{2}$ /light gas separation materials, etc. [1,2]). Unfortunately, being liquid-phase materials, ILs have practical limitations when it comes to applications requiring materials with mechanical strength, form-factor stability, or processability. In order to overcome these physical limitations while retaining many of the desirable functional properties of ILs, polymerized ILs (PILs) have also been developed. PILs are typically prepared via the polymerization of IL monomers that contain a reactive group (or groups) on the monomer cation, corresponding anion, or both [3, 4]. Although PILs can be thought of as solid-state macromolecular analogs of ILs, they have less mobility and free volume on the molecular scale.

In recent years, one specific variation on traditional ILs and PILs that has emerged with the goal of obtaining the best properties of both materials has been the design and application of PIL/IL composites (sometimes called ion gels), in which free IL is homogeneously dispersed within a PIL matrix. These PIL/IL composite materials combine the high diffusion capabilities of a free IL with the mechanical strength, shape stability, and processability of a solid PIL. PIL/IL materials with hybrid liquid-solid properties have been successfully used as $\mathrm{CO}_{2} /$ light gas separation membranes, barrier coating materials for organic compounds, and ion-conducting membranes for battery and fuel cell applications [1, 2, 5-8].

PIL/IL materials reported in the literature have been almost entirely based on imidazolium ILs and IL monomers [9-13]. In addition, many of the PILs used in these composites were prepared via free-radical chain-addition polymerization of IL monomers containing a reactive vinyl group, while significantly fewer examples utilizing step-growth (i.e., condensation) polymerization have been studied. Examples of imidazolium-based PIL/IL materials made by step-growth include the work of Lee et al., who reported the ionic conductivity of polyester-based imidazolium PILs; the work of McDanel et al., who reported the gas sorption abilities of epoxide-amine imidazolium PIL/IL hybrids; and the work of Gao et al., who reported bis-hydroxyl imidazolium components incorporated into a polyurethane PIL $[14,11,15]$. There are also few examples of cross-linked PILs, where the cross-links improve the microstructure and mechanical properties of the PIL matrix. In these cases, the cross-linking IL monomers were divinyl-based or underwent Michael addition to induce cross-linking [16-18, 12, 19].

An alternative to imidazolium-based ILs and PILs is the use of ammonium-based analogues, which offer certain advantages over their more common imidazolium-based counterparts. For example, quaternary ammonium-based ILs and IL monomers have more options for functionalizing their chemical structures compared to their imidazolium analogs. This is because the number of commercially available organic amine starting materials for IL monomer preparation is significantly higher than that of 
imidazole-based starting materials. In addition, imidazole rings can only be conveniently alkylated or selectively functionalized once at each of the two imidazole ring $\mathrm{N}$ atoms, whereas amine starting materials can be selectively alkylated or functionalized many more times per $\mathrm{N}$ atom, depending on whether the starting amine is primary, secondary, or tertiary $[20,21]$. The synthesis of quaternary ammonium-based ILs and IL monomers is also simpler and uses less expensive precursor materials than the synthesis of analogous imidazolium ILs and monomers. However, the chemical properties of ammonium-based ILs and PILs have traditionally limited their practical application. Compared to their imidazolium counterparts, ammonium-based ILs and PIL materials have lower thermal and electrical stabilities due to their tendency to undergo Hofmann elimination or a reverse Mentshutkin reaction under high-temperature conditions [15, 22, 23]. As a result, few examples of ammonium-based PILs have been reported for thermal, mechanical, and electrochemical applications. Also, the ammonium PIL systems previously reported often only consist of just the ammonium PIL rather than a PIL/IL hybrid material. Moreover, these ammonium PILs were nearly all prepared by free-radical polymerization and non-crosslinked in nature [24-28].

Herein, we present the first example of a cross-linked ammonium PIL/IL system based on stepgrowth polyurethane chemistry. This PIL/IL platform is prepared by the reaction of quaternary ammonium-based diol ( $\left.\mathbf{A}_{\mathbf{2}}\right)$ and triol ( $\left.\mathbf{A}_{3}\right)$ IL monomers (where $\mathbf{A}=$ an alcohol ( $\left.-\mathrm{OH}\right)$ group) with a commercially available diisocyanate monomer $\left(\mathbf{B}_{2}\right.$, where $\mathbf{B}=$ an isocyanate $(-\mathrm{N}=\mathrm{C}=\mathrm{O})$ group $)$, using a free ammonium IL as polymerization solvent that is incorporated into the final composite material. The structures of the specific ammonium IL $\mathbf{A}_{\mathbf{2}}$ and $\mathbf{A}_{\mathbf{3}}$ monomers prepared, the di-isocyanate $\mathbf{B}_{\mathbf{2}}$ monomer used, and the ammonium ILs used are shown in Scheme 1 below, along with a generalized structure of the resulting cross-linked polyurethane-based PIL/IL composite. We characterized the gel curing times of the ammonium IL diol and triol monomers as a function of their structure, and the thermal and mechanical properties of free-standing cross-linked PIL/IL films as a function of their composition. We also evaluated the resulting cross-linked PIL/IL films for their thermal stability under air and inert atmosphere, their ability to act as sorptive barrier coatings for volatile toxic organic liquids [29, 30], and their variable-temperature ion conductivity behavior. In general, we found that these new ammonium step-growth PIL/IL composites have better thermal stability than previously reported ammonium-based PILs and PIL/IL blends [15, 17, 25, 28, 31-37]. Also, these composites were found to have good organic vapor suppression properties but were not as effective for organic liquid uptake as prior imidazolium based curable PIL/IL films. The ion conductivity values of our PIL/IL composites were found to be comparable to those of previous ammonium PIL/IL composites made by other polymerization methods $[15,28,38-43]$. 


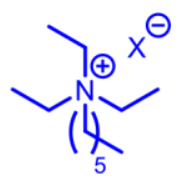

$\mathrm{X}=\mathrm{Br}: 1$

$\mathrm{X}=\mathrm{Tf}_{2} \mathrm{~N}: 2$

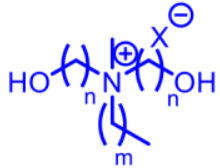

$\mathrm{m}=5, \mathrm{n}=2, \mathrm{X}=\mathrm{Br}: 3 \mathrm{a}$

$m=9, n=2, X=B r: 3 b$

$\mathrm{m}=3, \mathrm{n}=6, \mathrm{X}=\mathrm{Br}: 3 \mathrm{c}$

$\mathrm{m}=5, \mathrm{n}=2, \mathrm{X}=\mathrm{Tf}_{2} \mathrm{~N}: \mathbf{4 a}$

$\mathrm{m}=9, \mathrm{n}=2, \mathrm{X}=\mathrm{Tf}_{2} \mathrm{~N}: \mathbf{4 b}$

$\mathrm{m}=3, \mathrm{n}=6, \mathrm{X}=\mathrm{Tf}_{2} \mathrm{~N}: 4 \mathrm{c}$

$\mathrm{HO}-\mathrm{R}_{1}-\mathrm{OH}$

$\mathrm{A}_{2}$<smiles>CS(=O)(=O)NS(=O)(=O)C(F)(F)F</smiles><smiles>[X][N+](C)(CCO)CCO</smiles>

$\mathrm{m}=6, \mathrm{X}=\mathrm{Br}: \mathbf{5 a}$

$\mathrm{m}=10, \mathrm{X}=\mathrm{Br}: \mathbf{5 b}$

$\mathrm{m}=6, \mathrm{X}=\mathrm{Tf}_{2} \mathrm{~N}: \mathbf{6 a}$

$\mathrm{m}=10, \mathrm{X}=\mathrm{Tf}_{2} \mathrm{~N}: \mathbf{6 b}$<smiles>OP(O)O</smiles>

$\mathrm{A}_{3}$
TDI<smiles>Cc1ccc(N=C=O)cc1N=C=O</smiles>

$\mathrm{OCN}-\mathrm{R}_{3} \cdot \mathrm{NCO}$

$\mathrm{B}_{2}$

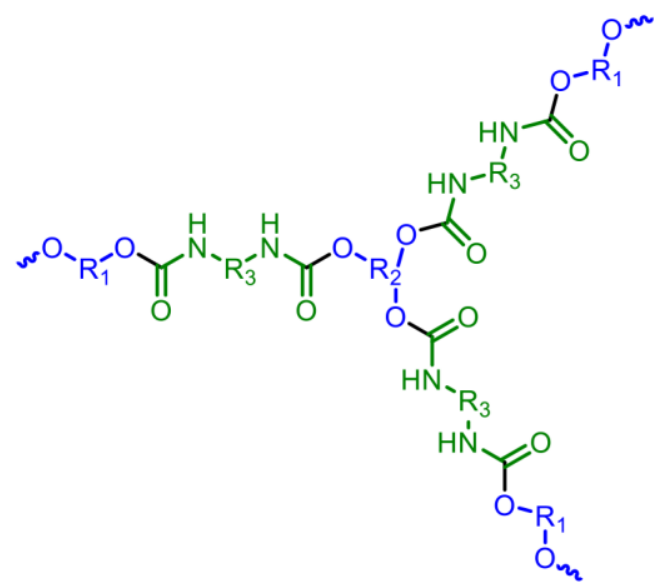

Scheme 1. The chemical structures of the ammonium ILs, the step-growth ammonium-diol $\left(\mathbf{A}_{2}\right)$ and -triol $\left(\mathbf{A}_{3}\right)$ IL monomers, and the di-isocyanate $\left(\mathbf{B}_{2}\right)$ monomer used, along with an idealized depiction of the structure of the resulting polyurethane-based PIL network formed. $\left(R_{1}\right.$ and $R_{2}$ in the generic polyurethane polymerization figure in the bottom half of Scheme 1 are the various alkyl-substituted ammonium salt spacer units between the -OH groups that are shown in the structures of the ammonium-diol monomers (i.e., $\mathbf{3 a}-\mathbf{c}$ and $\mathbf{4 a - c )}$ and -triol monomers (i.e., $\mathbf{5 a}$, $5 \mathbf{b}$ and $\mathbf{6 a}, \mathbf{6 b})$. Similarly, $\mathrm{R}_{3}$ represents the substituted arene linker between the two $-\mathrm{N}=\mathrm{C}=\mathrm{O}$ groups that is shown in the structure of the TDI monomer.) This new curable coating material is a two-component system consisting of an ammonium-based PIL network containing free IL.

\section{Materials and Methods}




\subsection{Materials}

$N$-Methyldiethanolamine, $n$-bromohexane, and $n$-bromodecane were received from SigmaAldrich and used without further purification. Triethylamine (TEA) and butylmethylamine were received from Sigma-Aldrich and distilled with $\mathrm{KOH}$ from Fisher Scientific. 10-Bromo-1-decanol and toluene diisocyanate (TDI) were received from TCI America. TDI was purified via vacuum distillation and stored under dry argon before use. Lithium bistrifluorosulfonimide $\left(\operatorname{LiTf}_{2} \mathrm{~N}\right)$ salt was purchased from $3 \mathrm{M}$. Acetonitrile was eluted through a silica plug before use. Dimethylformamide (DMF) was distilled and stored under inert atmosphere before use. All other solvents were used as received. Rubber test substrate samples were cut from a Hi-Run truck tire tube (TUN3001). Steel test substrate samples were cut from a 316 stainless-steel plate (McMaster-Carr) and painted with three coats of flat camouflage spray paint (Rust-Oleum). I-Chem septa jars (125-mL capacity) and Al foil cups were purchased from VWR.

\subsection{Instrumentation}

${ }^{1} \mathrm{H}$ and ${ }^{13} \mathrm{C}$ NMR spectra were obtained using DMSO- $d_{6}$ (for Br-containing ILs and IL monomers) and acetonitrile- $d_{3}$ (for $\mathrm{Tf}_{2} \mathrm{~N}^{-}$-containing ILs and IL monomers) as sample solvents. ${ }^{1} \mathrm{H}$ NMR spectra were acquired using a Bruker Avance-III 300 (300 MHz for $\left.{ }^{1} \mathrm{H}\right)$ NMR spectrometer. FT-IR measurements were performed using a Thermo Scientific Nicolet 6700 spectrometer. HRMS (ESI) analysis was performed by the Central Analytical Facility in the Dept. of Chemistry and Biochemistry at the University of Colorado, Boulder. Thermogravimetric analysis (TGA) was performed using a MettlerToledo Thermogravimetric Analyzer with a heating rate of $2{ }^{\circ} \mathrm{C} / \mathrm{min}$ from $50{ }^{\circ} \mathrm{C}$ to $600{ }^{\circ} \mathrm{C}$. TGA studies were performed with the samples under both $\mathrm{N}_{2}$ and air flow. Differential scanning calorimetry (DSC) was performed with a Mettler-Toledo DSC823 instrument attached to a Julabo FT100 immersion cooler under $\mathrm{N}_{2}$ flow. DSC analyses were performed over a temperature range of $-40{ }^{\circ} \mathrm{C}$ to $40{ }^{\circ} \mathrm{C}$ with a temperature ramp rate of $10{ }^{\circ} \mathrm{C} / \mathrm{min}$ and $2{ }^{\circ} \mathrm{C} / \mathrm{min}$ and monitored for any second-order thermal transitions. Film thickness was measured using a Cen-Tech digital thickness gauge at three different locations on the sample film and averaged. Thermomechanical property measurements were performed using a TA Instruments Q800 Dynamic Mechanical Analyzer. GC-MS measurements were performed using a Thermo-Finnigan PolarisQ Ion Trap GC-MS system with a column containing a stationary phase of 5\% phenyl and $95 \%$ methyl polysiloxane. GC-MS analyses were performed over a temperature range of 100 ${ }^{\circ} \mathrm{C}$ to $300{ }^{\circ} \mathrm{C}$ [30]. Ionic conductivity was determined by potentiostatic electrical impedance tests using a Gamry Instruments Reference 600 Potentiostat/Galvanostat/ZRA. The test cell fixture and sample films were contained in an LR Environmental Chamber Industrial Oven to control sample temperature.

\subsection{Synthesis and characterization of ammonium ILs and ammonium-alcohol IL monomers}

\subsubsection{N,N,N-Triethyl-1-hexanaminium bromide (1)}

Synthesized according to literature procedures. Characterization data matched those reported for this compound [44].

\subsubsection{N,N,N-Triethyl-1-hexanaminium bis(trifluoromethylsulfonyl)imide (2)}

Synthesized according to literature procedures. Characterization data matched those reported for this compound [44].

\subsection{3. $N$-Hexyl-N,N-bis(2-hydroxyethyl)-N-methanaminium bromide (3a)}

Synthesized according to literature procedure. Characterization data matched those reported for this compound [45]. 


\subsection{4. $N$-Decyl-N,N-bis(2-hydroxyethyl)-N-methanaminium bromide (3b)}

Synthesized according to literature procedures. Characterization data matched those reported for this compound [45].

\subsection{5. $N$-Butyl-N,N-bis(6-hydroxyhexyl)-N-methanaminium bromide (3c)}

Synthesized according to literature procedures with modifications [46]: $N$-Butylmethylamine (2.55 mL, $22 \mathrm{mmol}), \mathrm{K}_{2} \mathrm{CO}_{3}(5.95 \mathrm{~g}, 43 \mathrm{mmol})$, and $15 \mathrm{~mL}$ distilled DMF were mixed under inert atmosphere in a flask charged with a stir bar. 6-Bromo-1-hexanol $(3.90 \mathrm{~mL}, 22 \mathrm{mmol})$ was added to the mixture and allowed to stir for $14 \mathrm{~h}$. Afterward, the mixture was concentrated under vacuum. The residue was dissolved in diethyl ether $(10 \mathrm{~mL})$ and washed with $\mathrm{H}_{2} \mathrm{O}(3 \times 5 \mathrm{~mL})$ and saturated aq. $\mathrm{NaCl}$ solution $(1 \mathrm{x} 5 \mathrm{~mL})$. The ether was removed under vacuum to yield the tertiary amine intermediate as a yellow liquid (Yield: $1.84 \mathrm{~g}(46 \%))$. The intermediate $(0.97 \mathrm{~g}, 5.17 \mathrm{mmol})$ was then dissolved in a solution of 6bromo-1-hexanol $(0.94 \mathrm{~g}, 5.17 \mathrm{mmol})$ and $10 \mathrm{~mL}$ acetonitrile under an inert atmosphere. The reaction was heated at reflux for $24 \mathrm{~h}$. The solvent was removed in vacuo and the crude product was washed three times with dichloromethane. The bromide intermediate was isolated as a pale yellow viscous liquid. Yield: $1.52 \mathrm{~g}(80 \%) .{ }^{1} \mathrm{H}$ NMR (300 MHz, DMSO- $\left.d_{6}\right): \delta 4.39$ (t, 2H), 3.38 (q, 4H), $3.21(\mathrm{~m}, 6 \mathrm{H}), 2.96$ (s, 2H), $2.07(\mathrm{~s}, 3 \mathrm{H})), 1.60(\mathrm{~m}, 6 \mathrm{H}), 1.41(\mathrm{~m}, 4 \mathrm{H}), 1.30(\mathrm{~m}, 10 \mathrm{H}), 0.93(\mathrm{t}, 3 \mathrm{H}) .{ }^{13} \mathrm{C}$ NMR $(75 \mathrm{MHz}$, DMSO$\left.d_{6}\right): \delta 60.45,47.50,32.21,25.71,25.42,25.00,23.41,21.44,19.22,13.50,1.17$.

\subsection{6. $\mathrm{N}$-Hexyl-N,N-bis(2-hydroxyethyl)-N-methanaminium bis(trifluoromethylsulfonyl)imide (4a)}

Synthesized according to literature procedures [47]. Characterization data matched those reported for this compound [47].

\subsection{7. $N$-Decyl-N,N-bis(2-hydroxyethyl)-N-methanaminium bis(trifluoromethylsulfonyl)imide (4b)}

Compound 3b $(2.22 \mathrm{~g}, 6.51 \mathrm{mmol})$ was dissolved in deionized $\mathrm{H}_{2} \mathrm{O}(20 \mathrm{~mL})$, and $\operatorname{LiTf}_{2} \mathrm{~N}(1.96 \mathrm{~g}$, $6.84 \mathrm{mmol}$ ) was then added to the mixture and allowed to stir overnight at ambient temperature. The formed crude product was extracted with dichloromethane $(3 \times 10 \mathrm{~mL})$, and the organic layer was washed with $\mathrm{H}_{2} \mathrm{O}(4 \times 20 \mathrm{~mL})$. An aliquot of each wash was isolated, and to each aliquot was added one drop of $0.68 \%$ aq. $\mathrm{HNO}_{3}$ and two drops of $1 \mathrm{M}$ aq. silver nitrate solution. No further washes were performed once the silver nitrate test did not yield a silver halide precipitate. The organic layer was then concentrated in vacuo to yield the desired $\mathrm{Tf}_{2} \mathrm{~N}^{-}$salt monomer $4 \mathbf{b}$ as a pale yellow liquid. Yield: $3.06 \mathrm{~g}(87 \%)$. ${ }^{1} \mathrm{H} \mathrm{NMR}$ $\left(300 \mathrm{MHz}, \mathrm{CD}_{3} \mathrm{CN}-d_{3}\right): \delta 3.91(\mathrm{t}, 4 \mathrm{H}), 3.43(\mathrm{~m}, 4 \mathrm{H}), 3.32(\mathrm{q}, 4 \mathrm{H}), 3.05(\mathrm{~s}, 3 \mathrm{H}), 1.70(2 \mathrm{H}), 1.29(\mathrm{~m}, 14 \mathrm{H})$, $0.89(\mathrm{t}, 3 \mathrm{H}) .{ }^{13} \mathrm{C} \mathrm{NMR}\left(75 \mathrm{MHz}, \mathrm{CD}_{3} \mathrm{CN}-d_{3}\right): \delta 123.05,64.79,64.60,56.48,50.53,32.60,30.15,30.02$, 30.00, 29.69, 26.84, 23.38, 22.95, 14.38. HRMS $\left(\mathrm{ESI}^{+}\right)$calculated for $\left[\mathrm{C}_{15} \mathrm{H}_{34} \mathrm{NO}_{2}{ }^{+}\right]: 260.2584$; found: 260.2590. HRMS (ESI ${ }^{-}$calculated as $\left[\mathrm{Tf}_{2} \mathrm{~N}^{-}\right]$: 279.9173 ; found: 279.9185 . Since ILs are known to have combustion issues for elemental analysis [48], the ${ }^{1} \mathrm{H}$ and ${ }^{13} \mathrm{C}$ NMR spectra and ESI-HRMS spectra for the isolated compound are provided in the Supplementary Information to help confirm its purity in lieu of elemental analysis data.

\subsection{8. $N$-Butyl-N,N-bis(6-hydroxyhexyl)-N-methanaminium bis(trifluoromethylsulfonyl)imide (4c)}

Prepared via anion-exchange of compound $3 \mathbf{c}$ with $\operatorname{LiTf}_{2} \mathrm{~N}$ using the same procedure described above for the preparation of $\mathbf{4 b}$. Monomer $\mathbf{4 c}$ was isolated as a colorless viscous liquid. Yield: $2.75 \mathrm{~g}$ $(76 \%) .{ }^{1} \mathrm{H}$ NMR $\left(300 \mathrm{MHz}, \mathrm{CD}_{3} \mathrm{CN}-d_{3}\right): \delta 3.48(\mathrm{q}, 4 \mathrm{H}), 3.11(\mathrm{~m}, 6 \mathrm{H}), 2.86(\mathrm{~s}, 3 \mathrm{H}), 2.51(\mathrm{t}, 2 \mathrm{H}), 1.66(\mathrm{~m}$, $6 \mathrm{H}), 1.49(\mathrm{~m}, 4 \mathrm{H}), 1.36(\mathrm{~m}, 10 \mathrm{H}), 0.96(\mathrm{t}, 3 \mathrm{H}) .{ }^{13} \mathrm{C} \mathrm{NMR}\left(75 \mathrm{MHz}, \mathrm{CD}_{3} \mathrm{CN}-d_{3}\right): \delta 123.07,62.54,62.42$, 62.37, 48.99, 33.19, 26.71, 26.07, 24.70, 22.75, 20.29, 13.80. HRMS $\left(\mathrm{ESI}^{+}\right)$calculated for $\left[\mathrm{C}_{17} \mathrm{H}_{38} \mathrm{NO}_{2}{ }^{+}\right]$: 288.2903; found: 288.2907. HRMS (ESI ${ }^{-}$) calculated for $\left[\mathrm{Tf}_{2} \mathrm{~N}^{-}\right]$: 279.9173; found: 279.9180. Since ILs 
are known to have combustion issues for elemental analysis [48], the ${ }^{1} \mathrm{H}$ and ${ }^{13} \mathrm{C}$ NMR spectra and ESIHRMS spectra for the isolated compound are provided in the Supplementary Information to help confirm its purity in lieu of elemental analysis data.

\subsection{9. $N, N$-Bis-(2-hydroxyethyl)- $N$-(6-hydroxyhexyl)- $N$-methanaminium bromide (5a)}

Synthesized according to literature procedures with some modifications [44]. $\mathrm{N}$ methyldiethanolamine $(0.80 \mathrm{~mL}, 6.95 \mathrm{mmol}), 6$-bromo-1-hexanol $(1.00 \mathrm{~g}, 7.65 \mathrm{mmol})$, and $5 \mathrm{~mL}$ acetonitrile were mixed in a round-bottom flask charged with a stir bar. The reaction was heated to reflux and stirred at reflux for $24 \mathrm{~h}$. The product was concentrated in vacuo and recrystallized using acetonitrile/ethyl acetate. Yield: $1.87 \mathrm{~g}(90 \%) .{ }^{1} \mathrm{H}$ NMR (300 MHz, DMSO- $\left.d_{6}\right): \delta 5.24(\mathrm{t}, 2 \mathrm{H}), 4.38(\mathrm{t}$, $4 \mathrm{H}), 3.80(\mathrm{q}, 4 \mathrm{H}), 3.45(\mathrm{~m}, 4 \mathrm{H}), 3.37(\mathrm{~m}, 4 \mathrm{H}), 3.09(\mathrm{~s}, 3 \mathrm{H}), 1.67(\mathrm{~m}, 2 \mathrm{H}), 1.40(\mathrm{~m}, 2 \mathrm{H}), 1.27(\mathrm{~m}, 4 \mathrm{H}) .{ }^{13} \mathrm{C}$ NMR (75 MHz, DMSO- $\left.d_{6}\right): \delta 63.14,62.40,60.46,54.73,49.03,32.21,25.68,25.01,21.65$. Since ILs are known to have combustion issues for elemental analysis [48], the ${ }^{1} \mathrm{H}$ and ${ }^{13} \mathrm{C}$ NMR spectra for the isolated compound are provided in the Supplementary Information to help confirm its purity in lieu of elemental analysis data.

\subsubsection{0. $N$-(10-Hydroxydecyl)-N,N-bis-(2-hydroxyethyl)-N-methanaminium bromide (5b)}

Synthesized according to the same procedure used to prepare monomer 5a, except that 10-bromo1-decanol (6.43 g, $27.1 \mathrm{mmol})$ was used instead of 6-bromo-1-hexanol. Monomer $\mathbf{5 b}$ was isolated as a white solid. Yield: $10.45 \mathrm{~g}(84 \%) .{ }^{1} \mathrm{H}$ NMR $\left(300 \mathrm{MHz}, \mathrm{DMSO}-d_{6}\right): \delta 5.24(\mathrm{t}, 2 \mathrm{H}), 4.33(\mathrm{t}, 1 \mathrm{H}), 3.81(\mathrm{q}$, 4H), $3.44(\mathrm{q}, 4 \mathrm{H}), 3.35(\mathrm{~m}, 4 \mathrm{H}), 3.07(\mathrm{~s}, 3 \mathrm{H}), 1.67(\mathrm{~m}, 2 \mathrm{H}), 1.39(\mathrm{~m}, 2 \mathrm{H}), 1.25(\mathrm{~m}, 12 \mathrm{H}) .{ }^{13} \mathrm{C}$ NMR $(75$ MHz, DMSO- $\left.d_{6}\right): \delta 63.17,62.41,60.68,54.76,48.99,32.52,28.97,28.90,28.77,28.50,25.79,25.50$, 21.58. Since ILs are known to have combustion issues for elemental analysis [48], the ${ }^{1} \mathrm{H}$ and ${ }^{13} \mathrm{C}$ NMR spectra for the isolated compound are provided in the Supplementary Information to help confirm its purity in lieu of elemental analysis data.

\subsubsection{N,N-Bis-(2-hydroxyethyl)-N-(6-hydroxyhexyl)-N-methanaminium bis(trifluoromethylsulfonyl)imide (6a)}

Compound 5a $(1.95 \mathrm{~g}, 6.51 \mathrm{mmol})$ was dissolved in deionized $\mathrm{H}_{2} \mathrm{O}(20 \mathrm{~mL})$, and then $\mathrm{LiTf}_{2} \mathrm{~N}$ $(1.96 \mathrm{~g}, 6.84 \mathrm{mmol})$ was then added to the mixture, which was stirred overnight at ambient temperature. The formed crude product was extracted with ethyl acetate $(3 \times 10 \mathrm{~mL})$, and the organic layer was washed with $\mathrm{H}_{2} \mathrm{O}(4 \times 20 \mathrm{~mL})$. An aliquot of each wash was isolated, and to each aliquot was added one drop of $0.68 \%$ aq. $\mathrm{HNO}_{3}$ and two drops of $1 \mathrm{M}$ aq. silver nitrate solution. No further washes were performed once the silver nitrate test did not yield a silver halide precipitate. The organic layer was then concentrated in vacuo to yield the desired $\mathrm{Tf}_{2} \mathrm{~N}^{-}$salt monomer $6 \mathbf{a}$ as a clear liquid. Yield: $1.99 \mathrm{~g}(61 \%)$. ${ }^{1} \mathrm{H}$ NMR $\left(300 \mathrm{MHz}, \mathrm{CD}_{3} \mathrm{CN}-d_{3}\right): \delta 3.91(\mathrm{t}, 4 \mathrm{H}), 3.49(\mathrm{q}, 2 \mathrm{H}), 3.43(\mathrm{~m}, 4 \mathrm{H}), 3.33$ (quintet, 4H), $3.05(\mathrm{~s}$, $3 \mathrm{H}), 2.51(\mathrm{t}, 1 \mathrm{H}), 1.72(\mathrm{~m}, 2 \mathrm{H}), 1.48(\mathrm{~m}, 2 \mathrm{H}), 1.35(\mathrm{~m}, 4 \mathrm{H}) .{ }^{13} \mathrm{C} \mathrm{NMR}\left(75 \mathrm{MHz}, \mathrm{CD}_{3} \mathrm{CN}-d_{3}\right)$ : $\delta 123.06$, 64.83, 64.58, 62.34, 56.50, 50.55, 33.14, 26.70, 26.07, 22.99. HRMS (ESI ${ }^{+}$) calculated for $\left[\mathrm{C}_{11} \mathrm{H}_{26} \mathrm{NO}_{3}{ }^{+}\right]$: 220.1913; found: 220.1919. HRMS (ESI ${ }^{-}$) calculated for $\left[\mathrm{Tf}_{2} \mathrm{~N}^{-}\right]$: 279.9173; found: 279.9179. Since ILs are known to have combustion issues for elemental analysis [48], the ${ }^{1} \mathrm{H}$ and ${ }^{13} \mathrm{C}$ NMR spectra and ESIHRMS spectra for the isolated compound are provided in the Supplementary Information to help confirm its purity in lieu of elemental analysis data.

\subsubsection{2. $\mathrm{N}$-(10-Hydroxydecyl)-N,N-bis-(2-hydroxyethyl)-N-methanaminium} bis(trifluoromethylsulfonyl)imide $(\boldsymbol{6} \boldsymbol{b})$ 
Prepared via anion-exchange of compound $\mathbf{5 b}$ with $\mathrm{LiTf}_{2} \mathrm{~N}$ using the same procedure described above for the preparation of $\mathbf{6 a}$. Monomer $\mathbf{6 b}$ was isolated as a pale white viscous liquid. Yield: $6.17 \mathrm{~g}$ (78\%). ${ }^{1} \mathrm{H}$ NMR $\left(300 \mathrm{MHz}, \mathrm{CD}_{3} \mathrm{CN}-d_{3}\right): \delta 3.91(\mathrm{t}, 4 \mathrm{H}), 3.47(\mathrm{t}, 2 \mathrm{H}), 3.42(\mathrm{~m}, 4 \mathrm{H}), 3.34(\mathrm{~m}, 4 \mathrm{H}), 3.05(\mathrm{~s}$, $3 \mathrm{H}), 2.45(\mathrm{t}, 1 \mathrm{H}), 1.70(\mathrm{~m}, 2 \mathrm{H}), 1.47(\mathrm{~m}, 2 \mathrm{H}), 1.31(\mathrm{~m}, 12 \mathrm{H}) .{ }^{13} \mathrm{C}$ NMR $\left(75 \mathrm{MHz}, \mathrm{CD}_{3} \mathrm{CN}-d_{3}\right): \delta 123.06$, 64.82, 64.64, 62.67, 56.51, 50.53, 49.95, 33.56, 30.13, 29.94, 29.65, 26.83, 26.60, 22.95. HRMS (ESI $\left.{ }^{+}\right)$ calculated for $\left[\mathrm{C}_{15} \mathrm{H}_{34} \mathrm{NO}_{3}{ }^{+}\right]$: 276.2539; found: 276.2545 . HRMS (ESI ${ }^{-}$calculated for $\left[\mathrm{Tf}_{2} \mathrm{~N}^{-}\right]$: 279.9173 ; found: 279.9185 . Since ILs are known to have combustion issues for elemental analysis [48], the ${ }^{1} \mathrm{H}$ and ${ }^{13} \mathrm{C}$ NMR spectra and ESI-HRMS spectra for the isolated compound are provided in the Supplementary Information to help confirm its purity in lieu of elemental analysis data.

\subsection{Curing rate studies of the ammonium-diol and-triol monomers with TDI in IL solvent}

Coating mixtures to determine the relative curing rates of the different ammonium-diol and -triol monomers with TDI were prepared by a two-vial method. In this method, two separate stock solutions containing the two monomers and the polymerization catalyst in IL solvent were prepared. Solution A was prepared by combining a molar equiv. of the selected ammonium-alcohol monomer that gave equivalent amounts of $-\mathrm{OH}$ and $-\mathrm{TDI}$ functional groups in the overall mixture (i.e. 1 equiv. ammonium diols, 0.67 equiv. ammonium-triols, since TDI has a functionality of 2), 0.1 molar equiv. of 1,4diazabicyclo[2.2.2] octane (DABCO) as a polymerization catalyst, and 0.525 molar equiv. of the free IL 2 in a 1.5-dram vial. The other solution (Solution B) was prepared by combining 1 molar equiv. of TDI and 0.525 molar equiv. of the free IL in a 1.5-dram glass vial. Each vial was dried and degassed for $1 \mathrm{~h}$ under dynamic vacuum (ca. 100 mtorr) with stirring. A specific mass of Solution A and Solution B (based on delivering an equivalent number of moles of $-\mathrm{OH}$ groups and $-\mathrm{N}=\mathrm{C}=\mathrm{O}$ groups) was pipetted onto two separate $\mathrm{NaCl}$ salt plates at atmospheric conditions and pressed together before being inserted into the FT-IR spectrometer to track the degree of polymerization conversion. See the Supplementary Information for example FT-IR spectra of these mixtures while curing.

The integration of the isocyanate peak $\left(2220-2330 \mathrm{~cm}^{-1}\right.$, baseline-corrected over the same range) was monitored over time relative to the integration of the aromatic $\mathrm{C}=\mathrm{C}$ peak $\left(1505-1405 \mathrm{~cm}^{-1}\right.$, basecorrected over the same range). The gel point was determined by Carothers statistical analysis based on the stoichiometric ratio of the alcohol to the isocyanate, and the reaction was quantitatively monitored over time to track the disappearance of the isocyanate peak (100\% disappearance for the diols relative to the integrated area of the isocyanate peak at $t=0,83 \%$ disappearance for the triols). The gel point conversion values for these stoichiometric (ammonium-diol + TDI) and (ammonium-triol + TDI) reaction mixtures were calculated using Equation 1, where $p_{c}$ is the gel point conversion value, and $f_{a v}$ is the average monomer functionality in the polymerization mixture. $f_{\mathrm{av}}$ in each step-growth (S-G) polymerization mixture was calculated using Equation 2, where $N_{A m-\mathrm{OH}}$ is the number of moles of the selected ammonium-alcohol monomer (i.e., diol or triol), $N_{\mathrm{TDI}}$ is the number of moles of TDI in the polymerization, $f_{A m-\mathrm{OH}}$ is the functionality of the ammonium-alcohol monomers used (i.e., $f_{A m-O H}=2$ for the diols; $f_{\mathrm{Am}-\mathrm{OH}}=3$ for the triols), and $f_{\mathrm{TDI}}$ is the functionality of TDI (i.e., $f_{\mathrm{TDI}}=2$ for a di-isocyanate). Equations 1 and 2 are from Carothers gelation theory [49], which assumes a stoichiometric balance of complementary reactive groups in the S-G polymerization.

$$
\begin{gathered}
p_{c}=\frac{2}{f_{a v}}(1) \\
f_{a v}=\frac{\left(N_{A m-O H} * f_{A m-O H}\right)+\left(N_{T D I} * f_{T D I}\right)}{N_{A m-O H}+N_{T D I}}
\end{gathered}
$$




\subsection{PIL/IL bulk-cured film preparation}

Stock solutions of the ammonium-diol and -triol monomers plus DABCO (Solution A) in IL 2 and of TDI in IL 2 (Solution B) were prepared and dried/degassed according to the two-vial method described above. However, only .0025 molar equiv. of DABCO was used in preparing Solution A in order to reduce the $S-G$ polymerization reaction rate and avoid premature curing when the solutions were combined to initiate curing. The specific masses of Solution A and Solution B were based on delivering an equivalent number of moles of $-\mathrm{OH}$ groups and $-\mathrm{N}=\mathrm{C}=\mathrm{O}$ functional groups. The solutions were then combined in a glass vial at atmospheric conditions, vortexed for ca. $3 \mathrm{~s}$ and then transferred via pipette onto a $25 \mathrm{~mm} \times 25 \mathrm{~mm}$ glass slide treated with Rain- $\mathrm{X}^{\mathrm{TM}}$. The polymerization mixture was then placed in a vacuum chamber under Ar and allowed to cure for $48 \mathrm{~h}$ at ambient temperature. After curing, the resulting film was then removed from the glass slide with a razorblade. See the Supplementary Information for photographs of cured, free-standing PIL/IL films prepared by this method.

\subsection{Thermomechanical property characterization of the cured PIL/IL films}

The cured films were cut into ca. 1-mm-thick rectangular strips, and their dimensions were inputted into the DMA instrument software. The films were inserted into the DMA instrument using a two-point tension clamp system and held isothermally at $30{ }^{\circ} \mathrm{C}$ for $5 \mathrm{~min}$ before the experiment began. The stress-strain experiments were set up with a preload force of $0.0001 \mathrm{~N}$, a force ramp of $0.3 \mathrm{~N} / \mathrm{min}$, and an upper force limit of $10.0 \mathrm{~N}$. The films were monitored until the fracture point. See the Supplementary Information for an example DMA profile of a cured PIL/IL film.

DSC studies on both the standing and solvent-cast films indicated no observable thermal transitions between $-40{ }^{\circ} \mathrm{C}$ and $40^{\circ} \mathrm{C}$. See the Supplementary Information for an example DSC thermogram of a cured PIL/IL film.

\subsection{TIC vapor uptake and liquid extraction assays}

\subsubsection{TIC vapor uptake measurements}

The vapor test was performed as described in the procedure by Voss et al. [29]: $960 \mathrm{mg}$ total of the coating mixture was prepared via the free-standing film preparation method described above. The substrate of interest was placed on an $\mathrm{Al}$ foil cup in an aluminum metal mold inside of the septa-jar. 40 $\mathrm{mg}$ of $o$-dichlorobenzene $(o$-DCB) was pipetted onto the substrate. The two coating solutions were combined, mixed, and pipetted onto the substrate. The septa-jar was sealed with electrical tape for $24 \mathrm{~h}$. A syringe was then used to collect a 5- $\mu \mathrm{L}$ gaseous sample of the headspace above the coating and analyzed it using GC-MS.

\subsubsection{TIC liquid extraction measurements}

The liquid extraction test was performed using the same procedure described by Voss, et. al. with some modifications [29]. The coating prepared in the vapor uptake test was removed using a razorblade and Kim-Wipe. The substrate was placed in a 10-oz screw-top jar with a stir bar. Over the course of $24 \mathrm{~h}$, three aliquots of $10 \mathrm{~mL}$ of $\mathrm{CH}_{2} \mathrm{Cl}_{2}$ were added to the jar and allowed to stir with the substrate. The combined aliquots were collected and diluted. A known quantity of an internal standard, $n$-dodecane, was added to the diluted solution. A syringe was then used to collect a 1- $\mu \mathrm{L}$ liquid sample, which was analyzed by GC-MS. The amount of $o$-DCB in the $\mathrm{CH}_{2} \mathrm{Cl}_{2}$ solution was determined using a calibration curve based on the added internal standard (see the Supplementary Information). 


\subsection{Variable- temperature ionic conductivity tests}

The ionic conductivity of the cured PIL/IL films was measured by electrical impedance spectroscopy (EIS) using a potentiostat and a custom-made electrochemical sample cell that contained two stainless-steel electrodes with an active area of $1 \mathrm{~cm}^{2}$. The AC voltage applied was $100 \mathrm{mV}$, while the frequency was varied between $1 \mathrm{~Hz}-1 \mathrm{MHz}$ during testing. The real resistance was determined by extrapolation of the $\mathrm{x}$-intercept of the real and imaginary impedance domains on a Nyquist plot [50]. The ion conductivity $\left(\mathrm{S} / \mathrm{cm}=\mathrm{ohm}^{-1} \times \mathrm{cm}^{-1}\right)$ was determined by equation 3 :

$$
\sigma=\frac{l}{Z A}
$$

where $A$ is the surface area of the film $\left(\mathrm{cm}^{2}\right), l$ is the thickness of the film $(\mathrm{cm})$, and $Z$ is the real resistance (ohms) collected from the $\mathrm{x}$-intercept of a Nyquist plot from the AC impedance measurements. See the Supplementary Information for an example Nyquist plot obtained from a cured PIL/IL sample film. Ion conductivity measurements were made at several temperatures to determine the effect of temperature on ion conductivity for each type of cured PIL/IL film prepared.

\section{Results and Discussion}

\subsection{Monomer selection and synthesis}

Polyurethane S-G chemistry (i.e., the reaction of multifunctional alcohol monomers with multifunctional isocyanate monomers) was selected due to its rapid reaction speed, control over linear polymer molecular weight and degree of cross-linking in network formation, and lack of volatile byproducts produced during reaction [49] (which is an important consideration in organic vapor containment applications [29, 30]). In addition, it was important that the chemical structures of the IL monomers and the composition of the S-G polymerization mixtures (including the amount of linear vs. cross-linking monomers and the amount of free IL incorporated) be easily varied, in order to tune certain physical properties (i.e., flexibility, curing time) of the resulting cross-linked PIL/IL materials. Because of this requirement, the first objective of this work was to determine the type of multifunctional ammonium IL monomers and free IL solvent to be used in preparing the S-G PIL/IL composite materials.

Bifunctional and trifunctional alcohol-containing ammonium IL monomers were to selected to perform the polyurethane S-G chemistry with a commercial multifunctional isocyanate monomer because of the commercial availability of bis- and tris(alcohol)-functionalized tertiary amines available for quaternization. $\mathrm{Tf}_{2} \mathrm{~N}^{-}$was selected as the anion for all of the ammonium-based IL compounds used in this study because (1) it allows nonsymmetrical ILs to be liquids at room temperature, and (2) it has been previously shown to act as a plasticizer for generating soft PIL materials [13]. Scheme 1 shows the complete list of the ammonium-diol and -triol IL monomers and ammonium ILs selected and synthesized for this study. In order to prepare the ammonium-diol and -triol IL monomers and ammonium-based free IL, the first step of their synthesis involved a Menshutkin reaction, a common method for preparing quaternary ammonium compounds from a tertiary amine and an alkyl halide. Following the alkylation step, anion metathesis of the resulting ammonium halide salts was performed to exchange the halide anions with $\mathrm{Tf}_{2} \mathrm{~N}^{-}$anions. The use of $\mathrm{H}_{2} \mathrm{O}$ in this anion-exchange step is important for isolation and purity because the halide salts are water-soluble but the $\mathrm{Tf}_{2} \mathrm{~N}^{-}$salts are not, thereby allowing for simple separation of the two species. To confirm complete $\mathrm{Tf}_{2} \mathrm{~N}^{-}$for halide exchange, during the workup of the 
ammonium $\mathrm{Tf}_{2} \mathrm{~N}^{-}$compounds the aqueous wash layers were tested with silver nitrate. The aqueous washes continued until there were no silver halide precipitate observed when the aqueous layer was contacted with silver nitrate [44]. Once the workup was complete, the resulting ammonium IL monomers and ILs were characterized via ${ }^{1} \mathrm{H}$ and ${ }^{13} \mathrm{C}$ NMR spectroscopy and high-resolution mass spectrometry (HRMS) to confirm their structures and purities. For the complete synthesis procedures and characterization data for each ammonium-alcohol IL monomer shown in Scheme 1, refer to the Experimental section and the Supplementary Information.

The multifunctional isocyanate monomer, TDI (Scheme 1) was selected due to its prevalence in industrial polyurethane resin production, its low cost, and its commercial availability. Additionally, recent work by Martin et al. showed that TDI is fairly soluble in ILs (for IL-based polymerizations) and that it was the fastest curing di-isocyanate monomer for use with imidazolium-alcohol IL-based polyurethane reactions compared to other commercially available di-isocyanates [30]. Although TDI itself is not an ILbased monomer, its ability to be dissolved in ILs affords sufficiently low vapor release in IL-solventbased polymerizations for applications requiring low vapor release, such as organic vapor containment [13].

\section{$3.2 S$-G curing kinetics of the ammonium-diol and-triol monomers with TDI}

After the ammonium-diol and -triol IL monomers and di-isocyanate monomer were selected, we next investigated the rate of S-G polymerization between these IL monomers and TDI under stoichiometric reaction conditions (i.e., with equimolar amounts of alcohol and isocyanate groups). The ideal curable PIL/IL material platform is one that can cure into a solid material in a short amount of time, with complete conversion of the alcohol and isocyanate functional groups into urethane linkages.

FT-IR spectroscopy was used to monitor the kinetics of the curing reaction of the individual ammonium-diol and -triol IL monomers with TDI with added free IL under the conditions described in Table 1, using protocols based on a prior paper for monitoring imidazolium-alcohol IL monomers reacting with TDI [30]. These curing tests were selected in order to simulate conditions in which the curable PIL/IL coating would be applied. The area of the $\mathrm{N}=\mathrm{C}$ stretching band from $2220-2330 \mathrm{~cm}^{-1}$ was measured in order to monitor the disappearance of the isocyanate peak during the reaction; and the aromatic ring $\mathrm{C}=\mathrm{C}$ stretch from $1405-1505 \mathrm{~cm}^{-1}$ was measured as an internal reference, since this bond does not react during urethane formation. The reaction was deemed complete when the polymerization reached its gel point, defined here as the point at which an immobile (non-flowable) polymer mixture is formed. Mathematically, the gel point was estimated by using a modified version of the Carothers equation (Equation 1), and the mixtures were considered fully cured at $100 \%$ conversion for ammoniumdiols $\mathbf{4 a - 4 c}$ and at $83 \%$ conversion for ammonium-triols $\mathbf{6 a}$ and $\mathbf{6 b}$.

Table 1: FT-IR curing results of alcohol-isocyanate polymerizations

\begin{tabular}{|c|c|c|c|c|}
\hline Entry & $\begin{array}{c}\text { Ammonium-Alcohol } \\
\text { IL Monomer } \\
\left(\mathbf{A}_{2} \text { or } \mathbf{A}_{3}\right)\end{array}$ & $\begin{array}{c}\text { Di- } \\
\text { isocyanate } \\
\text { Monomer } \\
\left(B_{2}\right)\end{array}$ & $\begin{array}{l}\text { Free IL } \\
\text { Solvent }\end{array}$ & $\begin{array}{l}\text { Curing Time } \\
\text { (min)* }\end{array}$ \\
\hline
\end{tabular}




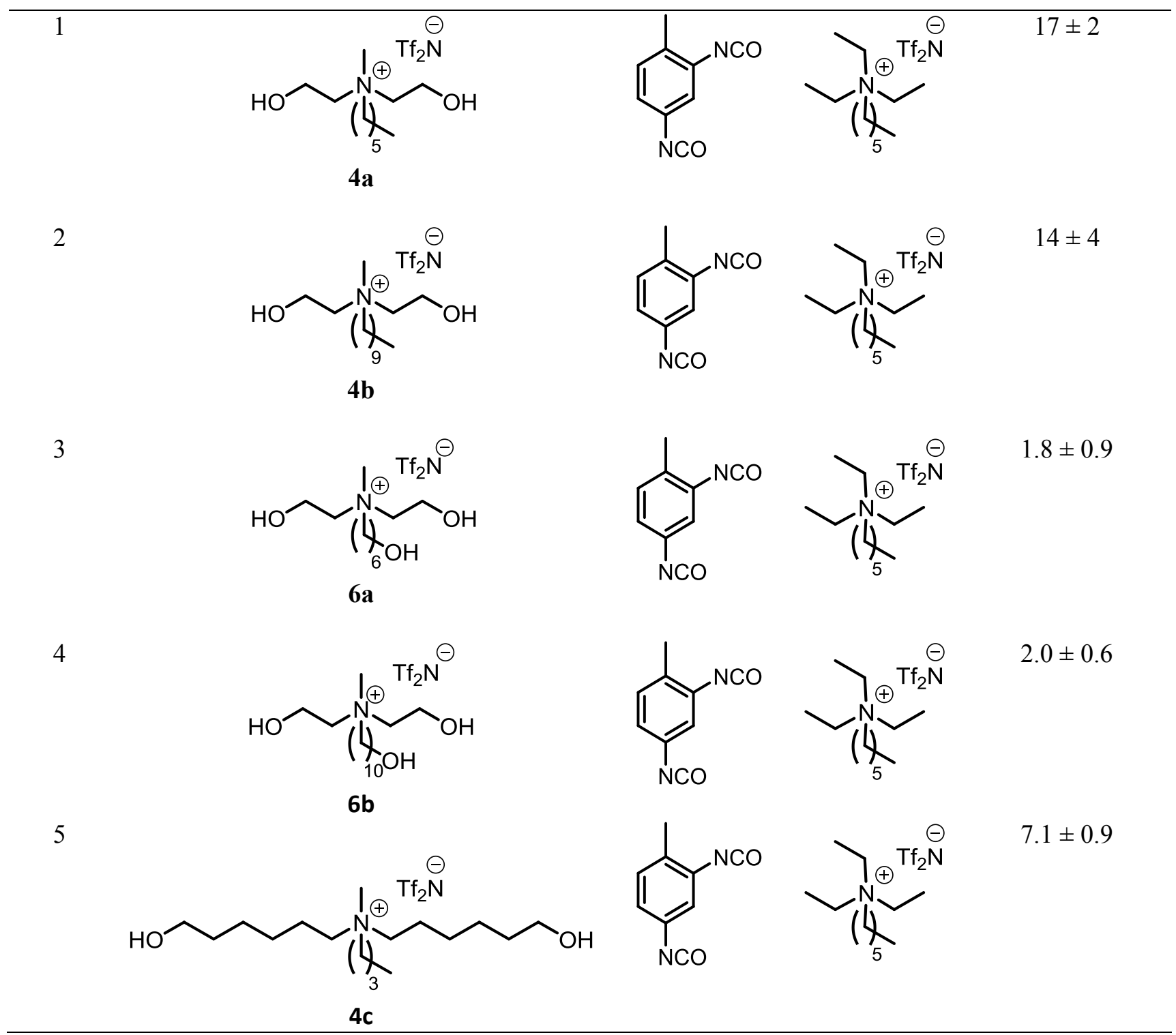

${ }^{a}$ FT-IR experiments were performed using 1 molar equiv. TDI $\left(\mathbf{B}_{2}\right), 1$ equiv. the total number of alcohol groups supplied by the ammonium-IL-diols $(\mathbf{4 a - c})$ or IL-triols $(\mathbf{6 a}-\mathbf{b}), 1.05$ equiv. free IL $\mathbf{2}$, and 0.1 equiv. DABCO at ambient temperature. Curing times were determined as a function of the reduction of the area of the isocyanate IR stretching band at $2220-2330 \mathrm{~cm}^{-1}$. The values shown are the averages of the results from 3 independent trials with standard deviation error bars.

As expected, the ammonium-triol monomers $6 \mathbf{a}$ and $\mathbf{6 b}$ cured more quickly with TDI than the corresponding diols $\mathbf{4 a}-\mathbf{c}$, based on the presence of the additional hydroxyl group on the former monomers that allows for extensive network formation. There was no observable effect of alkyl tail length on curing time among ammonium-diols $\mathbf{4 a}$ and $\mathbf{4 b}$. There also appeared to be no significant difference between the effect of the alkyl spacer length between the ammonium cation and hydroxy groups in the ammonium-triols $\mathbf{6 a}$ and $\mathbf{6 b}$. With the 6-carbon-spacer diol $\mathbf{4 c}$, the longer alkyl spacers in the alcohol arms were found to decrease the curing time. This effect is most likely due to the greater flexibility of the 6-carbon bis(alcohol) chains in $\mathbf{4 c}$ compared to the shorter 2-carbon alkyl spacers in $4 \mathbf{a}$ and $\mathbf{4 b}$, which allow them to more effectively come into contact with the isocyanate groups. 


\subsection{Preparation and characterization of ammonium-based PIL/IL composite films based on the reaction}

of monomers $(\boldsymbol{6} \boldsymbol{b}+\mathbf{4 b})$ with TDI

A series of curable PIL/IL films was then prepared and their mechanical and thermal properties were evaluated as a function of different ratios of linear and cross-linking ammonium-alcohol monomers. For this study, ammonium-alcohol IL monomers $\mathbf{4 b}$ and $\mathbf{6 b}$ (in different ratios) were selected for stoichiometric reaction with TDI for the following reasons: As described in the previous section, $\mathbf{4 b}$ exhibited the fastest curing times of the diol IL monomers tested under the same reaction conditions (Table 1). In addition to curing time, there were several other limitations to making a fully cured, solid PIL/IL film: The type of cross-linker monomer used in the film impacted the physical properties of the film. A fully cross-linked PIL/IL film using only $\mathbf{6 a}$, for example, resulted in a brittle film in which phase separation was observed. Using $\mathbf{6 b}$ in a fully cross-linked PIL/IL film resulted in a transparent, flexible, homogenous film (see Figure S10 in the Supplementary Information), and $\mathbf{6 b}$ and $\mathbf{4 b}$ monomers were miscible in one another. Therefore, $\mathbf{6 b}$ was selected as the cross-linking monomer in all the PIL/IL films prepared for property testing and applications evaluation.

The cured PIL/IL films were prepared from reacting varying ratios of monomers $\mathbf{6 b}$ and $\mathbf{4 b}$ with stoichiometric amount of TDI in free IL 2 using a bulk-cure method: Two precursor solutions denoted A and B were prepared. Solution A contained the $4 \mathbf{b}\left(\mathbf{A}_{2}\right), \mathbf{6 b}\left(\mathbf{A}_{3}\right)$, DABCO catalyst, and half of the mass of the free IL 2. Solution B contained the TDI $\left(\mathbf{B}_{2}\right)$ monomer and the other half of the mass of the free IL 2. Each solution was degassed under high dynamic vacuum (ca. 100 mtorr) and mixed briefly before being applied to a glass plate treated with Rain- $\mathrm{X}^{\mathrm{TM}}$. The films were allowed to cure for $48 \mathrm{~h}$ at room temperature (ca. $21^{\circ} \mathrm{C}$ ) in a vacuum chamber under an inert atmosphere (dry argon). They were deemed fully cured when they no longer flowed upon sample inversion and could be removed via razorblade without the formation of defects. To confirm near complete conversion of the reactive functional groups in the samples, the films were analyzed by attenuated total reflectance (ATR) FT-IR spectroscopy (ATRFTIR) to confirm the absence of an isocyanate peak at about $2300 \mathrm{~cm}^{-1}$.

The degree of cross-linking impacted whether a PIL/IL film cured into an integral solid film or not. PIL/IL blends with lower than 80:20 molar ratio of (6b:4b) resulted in films that were tacky and formed defects upon removal from the glass slide substrate. In addition, in preparing the bulk-cast films, the amount of DABCO (i.e., the urethane S-G polymerization catalyst) used was limited to 0.0025 molar equiv. relative to 1 molar equiv. of TDI. Using a higher molar equiv. amount of DABCO resulted in premature curing of solutions A and B upon mixing, making the mixture difficult to transfer to the glass slide without gelling/solidification.

The amount of 2 used as the free IL solvent was limited to a range of $46-47 \mathrm{wt} \%$ of the total mass of the film (ca. $1 \mathrm{~g}$ ). Use of a lower wt\% of free IL 2 with the monomer ratios and amounts described previously resulted in PIL/IL films that cured prematurely during mixing. In addition, use of a higher $\mathrm{wt} \%$ of free IL 2 resulted in composite films after polymerization that did not exhibit good mechanical properties (i.e., they were not solid films). To help with the formation of good, integral films during curing, each reactive component solution (i.e., solutions A and B) was degassed under dynamic vacuum ( $\leq 100$ mtorr), which eliminates the formation of bubbles in the cured final film. The specific wt $\%$ was selected based on maintaining the molar ratio of the components of the film (1 mol TDI: 1.05 mol 2, with a total mass of $\sim 1 \mathrm{~g}$ for the entire coating sample).

The mechanical and thermal properties of the resulting bulk cured films were then determined via dynamic mechanical analysis (DMA), and these results summarized in Table 2. Elastic modulus (E') and tensile strength $\left(\sigma_{\mathrm{T}}\right)$ data were collected for the bulk cured films. Based on the analysis of the stress-strain 
curves of the free-standing films, both their $E^{\prime}$ and $\sigma_{\mathrm{T}}$ values are significantly lower than other (dry) PILs in the literature, which is expected given the a significant amount of free IL as a plasticizer in our PIL/IL composite materials [31, 51]. However, our PIL/IL composite materials were comparable to or more flexible than other PIL/IL ion gel materials reported in the literature that utilized a PIL or nonionic polymer as the matrix material $[15,28,52-55]$. The $E$ ' values reported for similar materials ranged from 0.011 to $89 \mathrm{MPa}$, while the $\sigma_{\mathrm{T}}$ values ranged from 0.017 to $30 \mathrm{MPa}$. This result implies greater mechanical flexibility for our ammonium-based PIL/IL system than other PIL and PIL/IL materials that have been developed.

Table 2 also lists the thermal properties of the ammonium-based, cured PIL/IL films, as analyzed by thermogravimetric analysis (TGA) and differential scanning calorimetry (DSC). TGA was used to determine the thermal stability of the ammonium-based PIL/IL composite films in air and under dry $\mathrm{N}_{2}$ gas. The decomposition temperatures of the films were based on the observed temperature at which 10\%

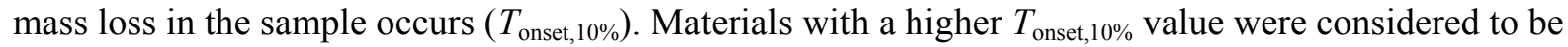
more thermally stable, and vice versa. Although there were some variations among the different degrees of cross-linking in each film, all films tested were thermally stable up until a high temperature (around $300{ }^{\circ} \mathrm{C}$ ). These results (summarized in Table 2) were not only comparable to other polymer-IL composite materials in the literature, but it also contradicts previous statements on ammonium PILs being inherently less thermally stable than other (usually imidazolium-based) PILs [17, 25, 28, 32, 33, 56].

Because of technical limitations in the DSC instrument, the lower temperature limit was $-40{ }^{\circ} \mathrm{C}$, so glass transition temperatures below $-40^{\circ} \mathrm{C}\left(T_{\mathrm{g}}\right)$ could not be detected. Also, no thermal step transition was detected over a range of $-40{ }^{\circ} \mathrm{C}$ to $40{ }^{\circ} \mathrm{C}$ at any cross-linking density of any of the films reported. Based on the physical properties of these films (soft, flexible, rubbery), the $T_{\mathrm{g}}$ values for these films are likely below $-40{ }^{\circ} \mathrm{C}$. The literature values for the $T_{\mathrm{g}}$ values of PIL films with similar physical properties all fall below $0{ }^{\circ} \mathrm{C}$, which further supports this conclusion [15, 17, 28, 31, 33-37].

Table 2: Mechanical and thermal properties of ammonium-based PIL/IL ammonium films. Bulk-cured films were prepared using 1 equiv. $\mathbf{B}_{2}$, (i.e., number of isocyanate groups $=$ number of alcohol groups supplied by $\left(\mathbf{A}_{\mathbf{2}}+\mathbf{A}_{\mathbf{3}}\right)$ ), 1.05 equiv. $\mathbf{2}$, and 0.0025 equiv. DABCO as a polymerization catalyst. Displayed ratios of $\left(\mathbf{A}_{2}: \mathbf{A}_{3}\right)$ correspond to the percent of alcohol functional groups contributed by the respective monomers. Elastic moduli were obtained using DMA at $30^{\circ} \mathrm{C}$. The standard deviation error values shown are the averages of 3 independent sample runs.

\begin{tabular}{|c|c|c|c|c|c|}
\hline $\begin{array}{c}\left(\mathrm{A}_{3}: \mathrm{A}_{2}\right) \text { Ratio } \\
\text { in Cured } \\
\text { PIL/IL Film }\end{array}$ & $\begin{array}{c}E^{\prime} \\
(\mathbf{M P a})\end{array}$ & $\begin{array}{c}\sigma_{\mathrm{T}} \\
(\mathrm{MPa})\end{array}$ & $\begin{array}{c}T_{\mathrm{g}} \\
\left({ }^{\circ} \mathbf{C}\right)\end{array}$ & $\begin{array}{l}T_{\text {onset, } 10 \%} \\
\left({ }^{\circ} \mathrm{C}, \text { air }\right)\end{array}$ & $\begin{array}{l}T_{\text {onset, } 10 \%} \\
\left({ }^{\circ} \mathrm{C}, \mathbf{N}_{2}\right)\end{array}$ \\
\hline $80: 20(\mathbf{6 b}: 4 b)$ & $0.035 \pm 0.003$ & $0.82 \pm 0.08$ & $<-40$ & 307 & 270 \\
\hline $90: 10(\mathbf{6 b}: \mathbf{4 b})$ & $0.042 \pm 0.004$ & $1.0 \pm 0.3$ & $<-40$ & 297 & 277 \\
\hline $100: 0(6 \mathbf{b}: 4 b)$ & $0.048 \pm 0.003$ & $1.05 \pm 0.01$ & $<-40$ & 307 & 284 \\
\hline
\end{tabular}

${ }^{a}$ Films were prepared with 1 molar equiv. TDI $\left(\mathbf{B}_{2}\right), 1$ equiv. the total number of alcohol groups supplied by the ammonium-diol (4b) and -triol (6b), 1.05 equiv. free IL 2 (46-47 wt. \%), and 0.0025 equiv. DABCO at ambient temperature.

\subsection{Evaluation of the toxic organic chemical containment properties of the ammonium-based curable PIL/IL films}

Initial work in the literature on volatile organic chemical containment systems utilizing IL-based coatings involved mixing an IL containing an organic gelator in order to prepare a spreadable, physicallygelled coating with exceptionally low vapor intrinsic pressure and good sorption of the organic chemical 
to be contained/removed. This IL physical gel system was based on imidazolium $\mathrm{Tf}_{2} \mathrm{~N}^{-}$ILs and shown to be effective in (a) blocking the vapor release of chemical warfare agent (CWA) simulants applied onto various substrate materials and (b) extracting the liquid CWA simulants soaked into these substrates [29]. More recent studies in IL-based toxic organic vapor and liquid containment coatings have shifted away from a physically gelled system to a curable, covalently bonded system involving an imidazolium PIL/IL polyurethane network that could be more easily handled and removed as a solid film afterwards. This latter system developed by Martin et al. was applied to substrates containing toxic industrial chemical (TIC) simulants rather than CWA simulants [30]. This curable imidazolium-based PIL/IL coating system was found to be very effective for (a) suppressing TIC vapor release from a contaminated substrate when applied as a coating that could be cured in situ; (b) withdrawing soaked-in liquid TIC from the sample interior; and (c) ease of removal as a flexible, solid film from the substrate surface with the trapped TIC inside. With our new ammonium-based curable PIL/IL materials, we wanted to compare their TIC uptake capabilities to that of the prior imidazolium-based PIL/IL films prepared for a similar application.

To test the TIC vapor containment and liquid uptake performance of the new ammonium-based curable PIL/IL materials, 100:0 mol:mol (6b:4b) PIL/IL films were prepared using a stoichiometric equivalent of TDI and $47 \mathrm{wt} \%$ total of free IL 2 in the sample. $o$-Dichlorobenzene $(o$-DCB) was selected as the TIC simulant based on its structural similarity to polychlorinated biphenyls (PCBs), environmental and health hazards once widely used but now regarded as persistent pollutants [57]. PCB decontamination and removal from surfaces has been an ongoing issue. The coating was prepared via the same method described in Section 3.3. The $o$-DCB was applied to a rubber test substrate and painted steel substrate and allowed to equilibrate for $1 \mathrm{~min}$ in a screw-top septa jar. Solutions A and B were mixed briefly to make a 100:0 mol:mol (6b:4b) coating and immediately applied to the substrate. The film was allowed to cure for $24 \mathrm{~h}$, and a GC glass syringe was used to take a 5- $\mu \mathrm{L}$ sample of the headspace above the film. Gas chromatography (GC) analysis indicated a peak corresponding to the $o$-DCB with a retention time of 2.58 min, and the integration under this peak was compared to an identical GC analysis of the headspace of an uncoated sample.

The results of these $o$-DCB vapor containment studies are shown in Figure 1. The curable PIL/IL film made with 100:0 mol:mol (6b:4b), a stoichiometric equivalent of TDI, and $47 \mathrm{wt} \%$ total of free IL 2 in the sample significantly reduced the amount of $o$-DCB vapor released into the container headspace. Compared to uncoated control samples of the same substrate materials, $88 \%$ of the $o$-DCB vapor was suppressed in the case of the PIL/IL-coated painted steel, and 79\% of the $o$-DCB vapor was suppressed in the case of the PIL/IL-coated rubber. These results are comparable to those achieved with the previously reported imidazolium-based curable PIL/IL coating system using the same TIC vapor assay [30]. 


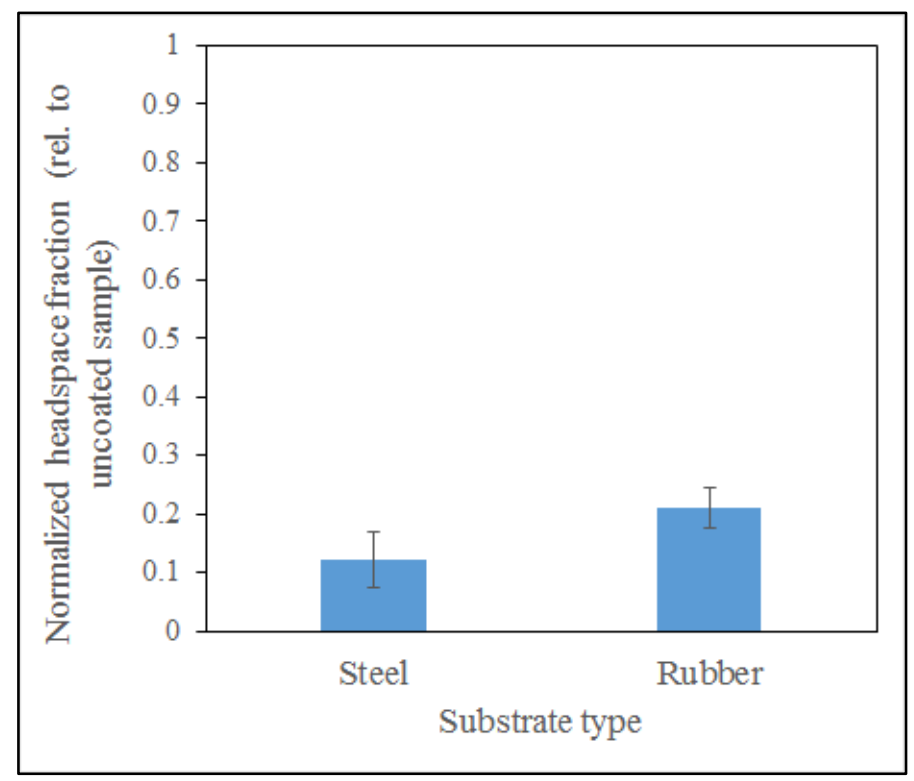

Figure 1: Results of the vapor headspace assays of curable ammonium-based PIL/IL films prepared using 100:0 mol:mol (6b:4b), a stoichiometric amount of TDI, and 47 wt \% free IL 2 on rubber and painted steel substrates contaminated with a set amount of $o$-DCB. The normalized fraction of gaseous $o$-DCB present in the headspace of the jar containing the coated substrates was compared to the amount of $o$-DCB present in the headspace of the uncoated control. The values shown are the averages of 3 trials with standard deviation error bars.

The same liquid $o$-DCB extraction assay that was performed on the imidazolium PIL/IL films in the work of Martin et al. [30] was also performed on the ammonium-based PIL/IL films. Following the $o$ DCB vapor headspace test, the ammonium-based PIL/IL film made with 100:0 mol:mol (6b:4b), a stoichiometric amount of TDI, and $47 \mathrm{wt} \%$ free IL 2 was removed from the substrate with a razorblade. The substrate was then washed with $\mathrm{CH}_{2} \mathrm{Cl}_{2}$ three times over the course of $24 \mathrm{~h}$ to extract the residual $o$ DCB remaining in the sample. The combined $\mathrm{CH}_{2} \mathrm{Cl}_{2}$ washes were diluted, and an internal standard ( $n$ dodecane) was introduced. The resulting solution was then analyzed using gas chromatography-mass spectrometry (GC-MS) analysis, and the ratio of the $o$-DCB GC peak to that of the internal standard was applied to a calibration curve to determine the number of moles of $o$-DCB extracted by $\mathrm{CH}_{2} \mathrm{Cl}_{2}$ from the substrate. The difference in that number from the original amount of $o$-DCB applied to the substrate in moles is the amount of $o$-DCB taken up by the PIL/IL coating. In addition, the results of the liquid extraction assays were compared to those obtained using uncoated substrates tested under the same conditions (uncoated controls). The liquid $o$-DCB extraction results for the curable ammonium PIL/IL coating on rubber and painted steel substrates are shown in the Supplementary Information (Figure S16). In general, the amount of liquid $o$-DCB uptake from rubber and painted steel substrates for the curable ammonium PIL/IL coatings was less than that for the previously reported imidazolium-based PIL/IL coatings using the same assay [30]. Based on the results in both types of substrates, the ammonium PIL/IL films sorbed less than $50 \%$ of the applied $o$-DCB.

Also, just like the previous imidazolium-based curable PIL/IL coating system [30], the current curable ammonium PIL/IL coating system based on IL-diol and -triol monomers is not sufficiently viscous in its initial monomeric form to prevent complete soak-through into very porous substrates (i.e., wood). Efforts to development more viscous initial curable PIL/IL formulations that allow surface application on wood and other very porous substrates are the subject of continued research. 


\subsection{Variable-temperature ionic conductivity behavior of the ammonium-based curable PIL/IL films}

Electrical impedance spectroscopy (EIS) was performed on free-standing samples of the cured ammonium PIL/IL films at different temperatures in order to determine their ionic conductivity behavior as a function of film composition, relative degree of cross-linking, and sample temperature. In these tests, the films were cut into squares and placed into a custom-made electrical impedance cell. The cell was placed into an environmental temperature chamber and attached to the working and counter leads. The cell and sample were allowed to equilibrate to the set temperature before the impedance measurements were taken. Potentiostatic EIS was used at each temperature to generate a Nyquist plot, and the real resistance value was extrapolated from the $\mathrm{x}$-intercept in the plot. The real resistance was then used to calculate the ionic conductivity based on sample test area and thickness [58]. See the Experimental section and the Supplementary Information for details on the specific equipment, procedures and equations used to determine sample ion conductivity from the collected EIS data.

The variable-temperature ion conductivity behavior for three sets of cured ammonium PIL/IL films with different (cross-linking IL monomer to linear monomer) ratios is presented in Figure 2. These cured PIL/IL films were prepared with (6b:4b) molar ratios of 80:20, 90:10, and 100:0; a stoichiometric amount of TDI; and $47 \mathrm{wt} \%$ free IL 2, all polymerized to approximately the same extent of conversion.

Collectively, these conductivity values are higher than those of IL-free PILs reported in the literature, which is not surprising given the conductivity benefits from the incorporation of free IL in the ammonium PIL/IL samples [11, 35, 37]. The observed conductivity values are comparable to those of $\mathrm{PIL} / \mathrm{IL}$ ion gels based on both ionic polymer/IL and non-ionic polymer/IL composite materials [15, 27, 50-55]. The ion gels reported in the literature cover a variety of chemical structures, including both imidazolium and ammonium-based ILs and polymers, S-G and chain-growth polymers, and cross-linked and linear polymer chains.

As can be seen in Figure 2a, the bulk-cured films, despite having higher resistance due to their innate thickness, had fairly high ionic conductivities. The more cross-linked PIL/IL films were more conductive than the less cross-linked films, especially at higher temperatures. For example, the film made with 80:20 mol:mol (6b:4b) (i.e., 80\% cross-linking monomer) had an ionic conductivity of $7.52 \times 10^{-5}$ $\mathrm{S} / \mathrm{cm}$ at $100{ }^{\circ} \mathrm{C}\left(1000 / \mathrm{T}=2.68 \mathrm{~K}^{-1}\right)$ while the 100:0 mol:mol (6b:4b) film (i.e., $100 \%$ cross-linking monomer) had a conductivity of $5.32 \times 10^{-4} \mathrm{~S} / \mathrm{cm}$ at the same temperature. This unusual trend in ion conductivity with cross-linking density was reproducible over at least 3 different independent sample films of the same composition. As can be seen in Figure $2 \mathrm{~b}$, upon cooling the sample from $100{ }^{\circ} \mathrm{C}$ to 20 ${ }^{\circ} \mathrm{C}$ following heating from $20{ }^{\circ} \mathrm{C}$ to $100{ }^{\circ} \mathrm{C}$, the films were observed to have a significant increase in their ionic conductivity at each temperature relative to the ionic conductivity measured during the heating cycle. The 100:0 mol:mol (6b:4b) in particular had the most dramatic increase in measured conductivity. An analysis of the films using normal optical microscopy over the same temperature range showed some spontaneous leaching/exclusion of free IL 2 from pores in the cured 100:0 mol:mol (6b:4b) film at the end of the initial heating cycle. The 80:20 mol:mol (6b:4b) and 90:10 mol:mol (6b:4b) PIL/IL films did not show any spontaneous leaching of $\mathbf{2}$ as a function of increasing sample temperature. The observed increase in ion conductivity with increasing PIL cross-link density in these ammonium PIL/IL materials seems to be counter-intuitive (i.e., more cross-linking typically leads to less mobility and free-volume). However, the exclusion of free IL onto the sample surfaces easily accounts for this irregularity, since free liquid-phase IL has a higher conductivity than the solid-state PIL/IL composite. Optical microscopy 
images of the 100:0 mol:mol (6b:4b) cured PIL/IL film over several heating cycles and the morphological changes are included in Figure S18 of the Supplementary Information.

(a)

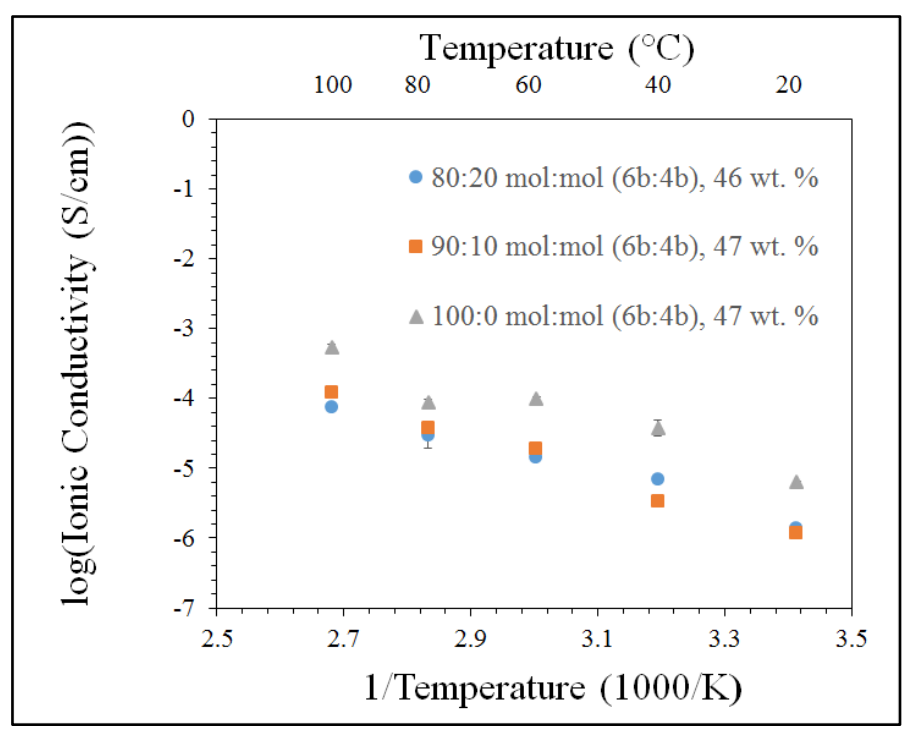

(b)

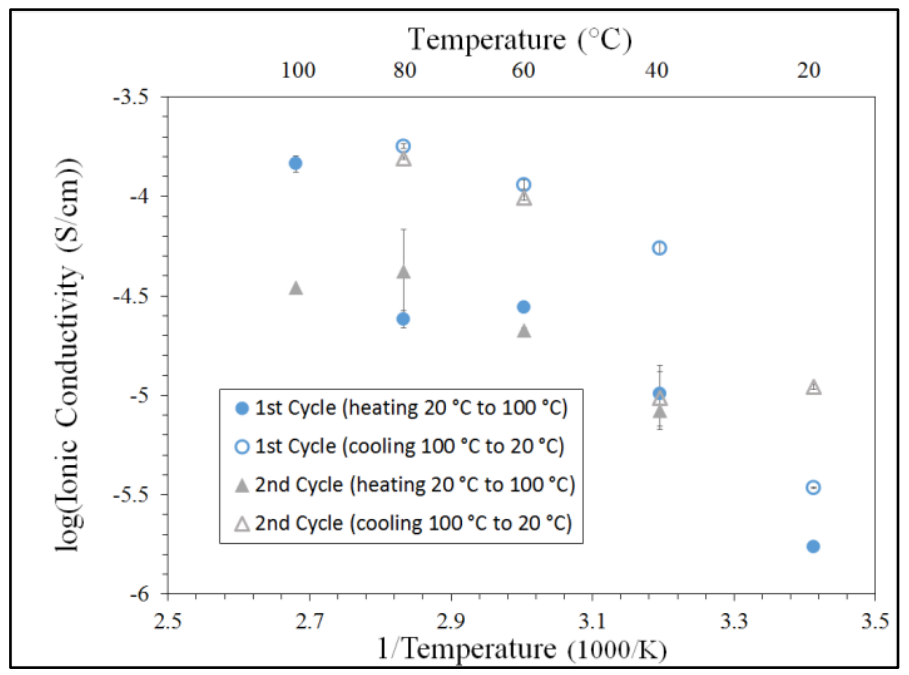

Figure 2: (a) Ionic conductivities for free- standing cured ammonium PIL/IL films with $\mathbf{6 b}: \mathbf{4 b}$ molar ratios ranging from 80:20 mol:mol (i.e., $80 \%$ cross-linking monomer) to 100:0 mol:mol (100\% cross-linking monomer). Each film was prepared with stoichiometric equivalents of $-\mathrm{OH}$ groups of the alcohol monomer(s) and $-\mathrm{N}=\mathrm{C}=\mathrm{O}$ groups of the isocyanate monomer along with the reported wt. \% of free IL 2. (b) Ionic conductivities for 100:0 mol:mol (6b:4b) free- standing cured ammonium PIL/IL film over two heating and cooling cycles. Each film was prepared with stoichiometric equivalents of $-\mathrm{OH}$ groups of the alcohol monomer(s) and $-\mathrm{N}=\mathrm{C}=\mathrm{O}$ groups of the isocyanate monomer along with 47 wt. \% of free IL 2

\section{Conclusions}


In summary, a series of ammonium-diol and -triol IL monomers was synthesized and used in S-G polymerization with the commercial di-isocyanate TDI in the presence of free ammonium IL to form new curable ammonium PIL/IL composite films/coatings. The use of polyurethane chemistry allows for the near-complete curing of the alcohol and isocyanate monomers to yield solid, homogenous, cross-linked polyurethane-based PIL/IL composite materials with no volatile side-product formation. The physical properties and curing rates of these PIL/IL films could be altered by tailoring the structures of the ammonium-alcohol IL monomers, the ratios of the linear vs. cross-linking IL monomers employed, and the amount of free IL in the curing reactions. Although ammonium-based PILs have been reported to be less thermally and electrochemically stable than their imidazolium counterparts in the literature, TGA results indicated a $T_{\text {onset, } 10}$ of up to $300{ }^{\circ} \mathrm{C}$ under air for the ammonium PIL/IL composites prepared in this study. In a TIC vapor suppression and liquid uptake assay using $o$-dichlorobenzene $(o$-DCB), these $\mathrm{PIL} / \mathrm{IL}$ coatings were found to suppress $88 \%$ of the $o$-DCB vapor on $o$-DCB-contaminated painted steel substrates and $79 \%$ of the $o$-DCB vapor on $o$-DCB-contaminated rubber substrates, relative to uncoated control samples. However, although effective for TIC vapor suppression, these ammonium PIL/IL coatings only sorbed less than $50 \%$ of the applied liquid $o$-DCB from the same test substrates, making them slightly less effective for this latter application than previously reported imidazolium-based curable PIL/IL coatings. Electrical impedance tests indicated comparable ionic conductivity values to other types of PIL/IL systems previously reported in the literature. However, it was visually observed that the more heavily cross-linked ammonium-based PIL/IL films were more prone to free IL leach-out with increasing sample temperature, which is mostly likely responsible for their unexpected higher ionic conductivity at elevated temperatures. Future work will involve preparing new curable ammonium PIL/IL systems based on a IL-alcohol prepolymer instead of IL-diol and -triol monomers, as a means of generating more viscous curable coatings that can be applied onto very porous materials (i.e., wood) without significant soak-through.

\section{Acknowledgments}

This work was supported primarily by the U.S. Army Research Office through an SBIR Phase 2 grant with TDA Research, Inc. (grant: W911NF- 15-P-0066) and partially by the U.S. Department of Energy (grant: DE-AR0000343). We thank Dr. B. J. Elliott at TDA Research for helpful discussions during the course of this work. We also thank Profs. R. D. Noble, Y. Ding, D. M. Walba, and R. K. Shoemaker at the University of Colorado, Boulder for use of their instruments and testing equipment.

\section{References}

[1] J.E. Bara, T.K. Carlisle, C.J. Gabriel, D. Camper, A. Finotello, D.L. Gin, et al., Guide to $\mathrm{CO}_{2}$ Separations in Imidazolium-Based Room-Temperature Ionic Liquids, Ind. Eng. Chem. Res. 48 (2009) 2739-2751.

[2] W. Lu, A.G. Fadeev, B. Qi, E. Smela, B.R. Mattes, J. Ding, et al., Use of Ionic Liquids for pi Conjugated Polymer Electrochemical Devices, Science 297 (2002) 983-987.

[3] J. Yuan, M. Antonietti, Poly(ionic liquid)s: Polymers expanding classical property profiles, Polymer 52 (2011) 1469-1482.

[4] H. Ohno, M. Yoshizawa, W. Ogihara, Development of new class of ion conductive polymers based on ionic liquids, Electrochim. Acta 50 (2004) 255-261.

[5] M.J. Muldoon, S.N.V.K. Aki, J.L. Anderson, J.K. Dixon, J.F. Brennecke, Improving carbon 
dioxide solubility in ionic liquids, J. Phys. Chem. B 111 (2007) 9001-9009.

[6] J. Lopez-Darias, V. Pino, J.L. Anderson, C.M. Graham, A.M. Afonso, Determination of water pollutants by direct-immersion solid-phase microextraction using polymeric ionic liquid coatings, J. Chromatogr. A 1217 (2010) 1236-1243.

[7] Y. Meng, V. Pino, J.L. Anderson, Role of counteranions in polymeric ionic liquid-based solidphase microextraction coatings for the selective extraction of polar compounds, Anal. Chim. Acta 687 (2011) 141-149.

[8] M.A.B.H. Susan, T. Kaneko, A. Noda, M. Watanabe, Ion gels prepared by in situ radical polymerization of vinyl monomers in an ionic liquid and their characterization as polymer electrolytes, J. Am. Chem. Soc. 127 (2005) 4976-4983.

[9] Y. Gu, T.P. Lodge, Synthesis and Gas Separation Performance of Triblock Copolymer Ion, Macromolecules 44 (2011) 1732-1736.

[10] P. Snedden, A.I. Cooper, K. Scott, N. Winterton, Cross-Linked Polymer - Ionic Liquid Composite Materials, Macromolecules 36 (2003) 4549-4556.

[11] M. Lee, U.H. Choi, D. Salas-De La Cruz, A. Mittal, K.I. Winey, R.H. Colby, et al., Imidazolium polyesters: Structure-property relationships in thermal behavior, ionic conductivity, and morphology, Adv. Funct. Mater. 21 (2011) 708-717.

[12] H. Nakajima, H. Ohno, Preparation of thermally stable polymer electrolytes from imidazoliumtype ionic liquid derivatives, Polymer 46 (2005) 11499-11504.

[13] M. Armand, F. Endres, D.R. MacFarlane, H. Ohno, B. Scrosati, Ionic-liquid materials for the electrochemical challenges of the future, Nat. Mater. 8 (2009) 621-629.

[14] W.M. McDanel, M.G. Cowan, T.K. Carlisle, A.K. Swanson, R.D. Noble, D.L. Gin, Cross-linked ionic resins and gels from epoxide-functionalized imidazolium ionic liquid monomers, Polymer 55 (2014) 3305-3313.

[15] R. Gao, M. Zhang, S.W. Wang, R.B. Moore, R.H. Colby, T.E. Long, Polyurethanes containing an imidazolium diol-based ionic-liquid chain extender for incorporation of ionic-liquid electrolytes, Macromol. Chem. Phys. 214 (2013) 1027-1036.

[16] T.K. Carlisle, G. Nicodemus, R. D., D.L. Gin, R.D. Noble, $\mathrm{CO}_{2} /$ light gas separation performance of cross-linked poly(vinylimidazolium) gel membranes as a function of ionic liquid loading and cross-linker content, J. Memb. Sci. 397-398 (2012) 24-37.

[17] C.P. Whittington, L.A. Daily, K.M. Miller, Crosslinked imidazolium-containing polyester networks containing a pendant imidazolium group: Swelling studies and thermal properties, Polymer 55 (2014) 3320-3329.

[18] S. Kim, K.M. Miller, Synthesis and thermal analysis of crosslinked imidazolium-containing polyester networks prepared by Michael addition polymerization, Polymer 53 (2012) 5666-5674.

[19] T.K. Carlisle, W.M. McDanel, M.G. Cowan, R.D. Noble, D.L. Gin, Vinyl-functionalized poly(imidazolium)s: A curable polymer platform for cross-linked ionic liquid gel synthesis, Chem. Mater. 26 (2014) 1294-1296.

[20] F.A. Carey, Organic Chemistry, 6th ed., McGraw-Hill, New York, 2006.

[21] J.G. Smith, Organic Chemistry, 3rd ed., McGraw-Hill, New York, 2011. 
[22] B. Singh, S.S. Sekhon, Ion conducting behaviour of polymer electrolytes containing ionic liquids, Chem. Phys. Lett. 414 (2005) 34-39.

[23] S.T. Hemp, M. Zhang, M.H. Allen, S. Cheng, R.B. Moore, T.E. Long, Comparing ammonium and phosphonium polymerized ionic liquids: Thermal analysis, conductivity, and morphology, Macromol. Chem. Phys. 214 (2013) 2099-2107.

[24] H.L. Ricks-Laskoski, A.W. Snow, Synthesis and electric field actuation of an ionic liquid polymer, J. Am. Chem. Soc. 128 (2006) 12402-12403.

[25] P. Cardiano, P.G. Mineo, F. Neri, S. Lo Schiavo, P. Piraino, A new application of ionic liquids: hydrophobic properties of tetraalkylammonium-based poly(ionic liquid)s, J. Mater. Chem. 18 (2008) 1253-1260.

[26] Y.N. Akayama, N.M. Atsubara, R.T. Anaka, Z.C. Ai, T.S. Hiono, H.S. Hirahama, et al., Synthesis and Properties of Poly ( $\varepsilon$-carprolactone)-based Poly(ester-urethane)s Having Quaternary Ammonium Groups, J. Jpn. Inst. Energy 93 (2014) 916-920.

[27] J. Tang, H. Tang, W. Sun, M. Radosz, Y. Shen, Low-pressure $\mathrm{CO}_{2}$ sorption in ammonium-based poly(ionic liquid)s, Polymer 46 (2005) 12460-12467.

[28] K. Matsumoto, T. Endo, Synthesis of ion conductive networked polymers based on an ionic liquid epoxide having a quaternary ammonium salt structure, Macromolecules 42 (2009) 4580-4584.

[29] B.A. Voss, R.D. Noble, D.L. Gin, Ionic liquid gel-based containment and decontamination coating for blister agent-contacted substrates, Chem. Mater. 24 (2012) 1174-1180.

[30] R.M. Martin, D.I. Mori, R.D. Noble, D.L. Gin, Curable Imidazolium Poly(ionic liquid)/Ionic Liquid Coating for Containment and Decontamination of Toxic Industrial Chemical-Contacted Substrates, Ind. Eng. Chem. Res. 55 (2016) 6547-6550.

[31] P.A. Gunatillake, G.F. Meijs, S.J. McCarthy, N. Sherriff, Polyurethane elastomers with low modulus and hardness based on novel copolyether macrodiols, J. Appl. Polym. Sci. 63 (1997) $1373-1384$.

[32] E.A. Weiber, P. Jannasch, Ion distribution in quaternary-ammonium-functionalized aromatic polymers: Effects on the ionic clustering and conductivity of anion-exchange membranes, ChemSusChem 7 (2014) 2621-2630.

[33] P.G. Mineo, L. Livoti, M. Giannetto, A. Gulino, S. Lo Schiavo, P. Cardiano, Very fast $\mathrm{CO}_{2}$ response and hydrophobic properties of novel poly(ionic liquid)s, J. Mater. Chem. 19 (2009) 8861-8870.

[34] H. He, M. Zhong, B. Adzima, D. Luebke, H. Nulwala, K. Matyjaszewski, A simple and universal gel permeation chromatography technique for precise molecular weight characterization of welldefined poly(ionic liquid)s, J. Am. Chem. Soc. 135 (2013) 4227-4230.

[35] D. Fragiadakis, S. Dou, R.H. Colby, J. Runt, Molecular Mobility, Ion Mobility and Mobile Ion Concentration in Poly(ethylene oxide) -based Polyurethane Ionomers, Macromolecules 41 (2008) 5723-5728.

[36] L.C. Hardy, D.F. Shriver, Chloride Ion Conductivity in a Plasticized Quaternary Ammonium Polymer, Macromolecules 17 (1984) 975-977.

[37] J. Bartels, A. Hess, H.S. Shiau, H.R. Allcock, R.H. Colby, J. Runt, Synthesis, morphology, and ion conduction of polyphosphazene ammonium iodide ionomers, Macromolecules 48 (2015) 111-118. 
[38] C.-W. Liew, S. Ramesh, A.K. Arof, Investigation of ionic liquid-based poly(vinyl alcohol) proton conductor for electrochemical double-layer capacitor, High Perform. Polym. 26 (2014) 632-636.

[39] M. Díaz, A. Ortiz, M. Isik, D. Mecerreyes, I. Ortiz, Highly conductive electrolytes based on poly([HSO $\left.\left.{ }_{3}-\mathrm{BVIm}\right][\mathrm{TfO}]\right) /\left[\mathrm{HSO}_{3}-\mathrm{BMIm}\right][\mathrm{TfO}]$ mixtures for fuel cell applications, Int. J. Hydrogen Energy. 40 (2014) 11294-11302.

[40] K. Põhako-Esko, M. Timusk, K. Saal, R. Lõhmus, I. Kink, U. Mäeorg, Increased conductivity of polymerized ionic liquids through the use of a nonpolymerizable ionic liquid additive, J. Mater. Res. 28 (2013) 3086-3093.

[41] M.G. Cowan, A.M. Lopez, M. Masuda, Y. Kohno, W.M. McDanel, R.D. Noble, et al., Imidazolium-Based Poly(ionic liquid)/Ionic Liquid Ion-Gels with High Ionic Conductivity Prepared from a Curable Poly(ionic liquid), Macromol. Rapid Commun. 37 (2016) 1150-1154.

[42] S.K. Deraman, N.S. Mohamed, R.H.Y. Subban, Conductivity and electrochemical studies on polymer electrolytes based on poly vinyl (chloride) - ammonium triflate-ionic liquid for proton battery, Int. J. Electrochem. Sci. 8 (2013) 1459-1468.

[43] R. Leones, C.M. Costa, A. V Machado, J.M.S.S. Esperança, M.M. Silva, S. Lanceros-méndez, Development of solid polymer electrolytes based on poly(vinylidene fluoride-trifluoroethylene) and the $[\mathrm{N} 1112(\mathrm{OH})]\left[\mathrm{NTf}_{2}\right]$ ionic liquid for energy storage applications, Solid State Ionics 253 (2013) 143-150.

[44] T. Floris, P. Kluson, L. Bartek, H. Pelantova, Quaternary ammonium salts ionic liquids for immobilization of chiral Ru-BINAP complexes in asymmetric hydrogenation of $\beta$-ketoesters, Appl. Catal. A Gen. 366 (2009) 160-165.

[45] J.H. Wynne, P.A. Fulmer, D.M. McCluskey, N.M. Mackey, J.P. Buchanan, Synthesis and development of a multifunctional self-decontaminating polyurethane coating, ACS Appl. Mater. Interfaces 3 (2011) 2005-2011.

[46] T. Sugiishi, H. Nakamura, Zinc(II)-catalyzed redox cross-dehydrogenative coupling of propargylic amines and terminal alkynes for synthesis of N-tethered 1,6-enynes, J. Am. Chem. Soc. 134 (2012) 2504-2507.

[47] A.A. Rosatella, F. Siopa, R.F.M. Frade, C.A.M. Afonso, New low viscous cholinium-based magnetic ionic liquids, New J. Chem. 40 (2016) 3124-3129.

[48] M.R. Schenkel, R. Shao, L.A. Robertson, B.R. Wiesenauer, N.A. Clark, D.L. Gin, New ionic organic compounds containing a linear tris(imidazolium) core and their thermotropic liquid crystal behaviour, Liq. Cryst. 40 (2013) 1067-1081.

[49] J.M.G. Cowie, V. Arrighi, Polymers: Chemistry and Physics of Modern Materials, 3rd ed., CRC Press, New York, 2008.

[50] G. Casalbore-Miceli, M.J. Yang, N. Camaioni, C.-M. Mari, Y. Li, H. Sun, et al., Investigations on the ion transport mechanism in conducting polymer films, Solid State Ionics 131 (2000) 311-321.

[51] Z.K. Zander, F. Wang, M.L. Becker, R.A. Weiss, Ionomers for Tunable Softening of Thermoplastic Polyurethane, Macromolecules 49 (2016) 926-934.

[52] L. Bao, J. Lei, J. Wang, Preparation and characterization of a novel antistatic poly(vinyl chloride)/quaternary ammonium based ion-conductive acrylate copolymer composites, J. Electrostat. 71 (2013) 987-993. 
[53] X. Ma, R. Usui, Y. Kitazawa, H. Kokubo, M. Watanabe, Photo-healable ion gel with improved mechanical properties using a tetra-arm diblock copolymer containing azobenzene groups, Polymer 78 (2015) 42-50.

[54] K. Hashimoto, K. Fujii, K. Nishi, T. Sakai, M. Shibayama, Nearly Ideal Polymer Network Ion Gel Prepared in pH-Buffering Ionic Liquid, Macromolecules 49 (2016) 344-352.

[55] T.K. Ly Nguyen, M.M. Obadia, A. Serghei, S. Livi, J. Duchet-Rumeau, E. Drockenmuller, 1,2,3Triazolium-Based Epoxy-Amine Networks: Ion-Conducting Polymer Electrolytes, Macromol. Rapid Commun. 37 (2016) 1168-1174.

[56] T.C. Rhoades, J.C. Wistrom, R. Daniel Johnson, K.M. Miller, Thermal, mechanical and conductive properties of imidazolium-containing thiol-ene poly(ionic liquid) networks, Polymer 100 (2016) 1-9.

[57] G.R. Lester, Catalytic destruction of hazardous halogenated organic chemicals, Catal. Today. 53 (1999) 407-418.

[58] E. Barsoukov, J.R. Macdonald, Impedance Spectroscopy, 2nd ed., Wiley Interscience, Hoboken, New Jersey, 2005. 